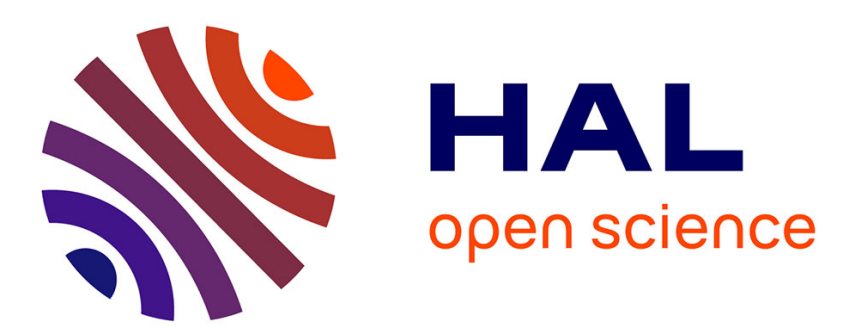

\title{
Strained Si1-xGex/Si Dots and Wires Grown by Selective Epitaxy
}

L. Vescan, R. Loo, A. Souifi, C. Dieker, S. Wickenhäuser

\section{To cite this version:}

L. Vescan, R. Loo, A. Souifi, C. Dieker, S. Wickenhäuser. Strained Si1-xGex/Si Dots and Wires Grown by Selective Epitaxy. Journal de Physique IV Proceedings, 1995, 05 (C5), pp.C5-55-C5-62. 10.1051/jphyscol:1995503 . jpa-00253759

\section{HAL Id: jpa-00253759 https://hal.science/jpa-00253759}

Submitted on 1 Jan 1995

HAL is a multi-disciplinary open access archive for the deposit and dissemination of scientific research documents, whether they are published or not. The documents may come from teaching and research institutions in France or abroad, or from public or private research centers.
L'archive ouverte pluridisciplinaire HAL, est destinée au dépôt et à la diffusion de documents scientifiques de niveau recherche, publiés ou non, émanant des établissements d'enseignement et de recherche français ou étrangers, des laboratoires publics ou privés. 


\title{
Strained $\mathrm{Si}_{1-x} \mathrm{Ge}_{\boldsymbol{x}} / \mathrm{Si}$ Dots and Wires Grown by Selective Epitaxy
}

\author{
L. Vescan, R. Loo, A. Souifi, C. Dieker and S. Wickenhäuser \\ Institut für Schicht- und Ionentechnik (ISI), Forschungszentrum Jülich GmbH, 52425 Jülich, Germany
}

\begin{abstract}
Selective epitaxial growth of $\mathrm{Si}_{1-x} \mathrm{Ge}_{x}$ was studied with the aim to fabricate quantum wires and dots. The selective deposition was performed by low pressure chemical vapor deposition with dichlorosilane and germane as precursors, at 0.1 Torr and $700^{\circ} \mathrm{C}$ in a radiation heated, cold wall, high vacuum, quartz reactor. Dislocation free strained dots and wires could be grown much thicker than the critical thickness for unpatterned area, because the critical thickness by formation of misfit dislocations increases when the window dimension is reduced. For $\mathrm{x}$ up to $20 \%$ it was found that for $10 \times 10 \mu \mathrm{m}^{2}$ dots the critical thickness increases by more than 4 times. The tendency of facet formation was exploited to realize laterally confined multiple quantum well dots and wires with sizes down to $50 \mathrm{~nm}$. Besides the emission from the (100) quantum well layers excitonic emissions from quantum well layers from flat $\{110\}$ facets and from islands in the (100) and $\{311\}$ facets were detected. All dots and wires luminesce stronly down to the lowest achieved dimension of $50 \mathrm{~nm}$, the integral intensity exceeding that from the substrate.
\end{abstract}

\section{INTRODUCTION}

Low-dimensional quantum-confinement has raised much interest due to the possibility to fabricate devices which could benefit from the predicted enhanced density of states and higher binding energy of excitons [1]. An enhanced density of states in the quantum wire heterostructures subbands should lead to a higher optical absorption and emission.

There are only few published papers on SiGe nanostructures in comparison with III-V materials. The fabrication techniques proposed and used so far can be divided into two categories.

(a) Self-organized methods take advantage of the Stranski-Krastanov growth mode (island growth) during the epitaxial growth of lattice mismatched systems [2]. The growth is performed on planar surfaces or on V-grooved patterned substrates. This technique was applied to realize SiGe islands incorporated into the active region of electroluminescent devices. An improved emission as compared to strained-layer structures was observed and explained by the reduction of non-radiative recombination by the spatial localization of excitons [3]. An alternative to island growth is the growth on $\mathrm{V}$-grooved $\mathrm{Si}$ substrates which leads to the accumulation of SiGe at the bottom of the V-grooves allowing the formation of $1 \mathrm{D}$ or $0 \mathrm{D}$ structures [4], [5].

(b) Free-standing structures were realized by several methods. The best known one is reactive ion etching which allowed to define features with minimum dimensions of $15 \mathrm{~nm}$ [6]. By local epitaxy with shadow masks $200 \mathrm{~nm}$ dots were fabricated by MBE with sidewalls determined solely by the growth process [7]. Lateral confinement can also be achieved by selective epitaxial growth in oxide 
windows on $\mathrm{Si}$ substrates. Usually chemical vapour deposition techniques with chlorine containing gases allow selective deposition. By this technique $80 \mathrm{~nm}$ dots were realized [8], while intense photoluminescence from sub-100 nm quantum well dots and wires on (100) surfaces was reported [9].

In this paper selective epitaxial growth (SEG) by low pressure chemical vapor deposition (LPCVD) was investigated with the aim to fabricate quantum wires and dots. There are several aspects which have to be taken into consideration when this technique is intended for devices. First, the growth rate and $\mathrm{Ge}$ content in the $\mathrm{Si}_{1-x} \mathrm{Ge}_{x}$ alloy should be independent on the pad size. When the growth is performed at total pressures low enough for the growth to be surface kinetic limited the growth is uniform at least down to $0.5 \mu \mathrm{m}$ lateral size of the oxide hole [10]. Second, usually facets develop during growth at the edges of the SEG area [11]. And third, the relaxation in small sized areas is retarded or even suppressed for pads smaller than $10 \times 10 \mu \mathrm{m}^{2}[12]$.

The SEG technique can in principle be applied in two ways to fabricate nanostructures. One is to use it in combination with electron beam lithography and deposit sub- $50 \mathrm{~nm}$ structures. Another way, followed here, is to exploit the facet formation and deposit the quantum well layer at such a height in the oxide hole as to have a (100) part of the SEG area as narrow as possible. So far, an extension of the (100) part of $50 \mathrm{~nm}$ for $\langle 110\rangle$ sidewall orientation was achieved. It resulted that, in spite of outer sharp facets, the quantum well layers inside the structure revealed a rounded form and in addition islands in the (100) and $\{311\}$ planes. However, the wires and dots luminesce stronly down to the lowest achieved dimension, the integral intensity exceeding that from the substrate.

\section{SELECTIVE GROWTH DETAILS}

The epitaxy was carried out in a cold wall, load-locked, high-vacuum LPCVD system. The reactor is a horizontal quartz tube with a $\mathrm{SiC}$ coated graphite holder. Heating is performed by external halogen lamps placed below and above the reactor tube with temperature control by three thermocouples placed inside the holder. The pumping system consisting of a turbomolecular pump for high vacuum is in parallel with a combination of root blower with a mechanical pump for pumping the reactive gases. The base pressure is $10^{-7}$ Torr. Three 3 " wafers can be homogeneously deposited in one run. The selective epitaxy reported here was carried out at a pressure of 0.12 Torr and temperature of $700^{\circ} \mathrm{C}$ using $\mathrm{SiCl}_{2} \mathrm{H}_{2}$ and $\mathrm{GeH}_{4}$ as source gases and $\mathrm{H}_{2}$ as carrier gas without addition of $\mathrm{HCl}$ and with a $\mathrm{Cl} / \mathrm{H}$ ratio of 0.05 . Growth rates and thermodynamic analysis for the $\mathrm{Si}-\mathrm{Ge}-\mathrm{Cl}-\mathrm{H}$ system were published elsewhere [13], [14]. Substrates were $2000 \Omega \mathrm{cm}$ p-type (100) Si with $200-500 \mathrm{~nm}$ thermal oxide patterned by optical or e-beam lithography and reactive ion etching. Arrays of rectangular holes parallel to $\langle 100\rangle$ or $\langle 110\rangle$ directions were realized. The wafers were then cleaned by the standard RCA cleaning, dipped in $2 \% \mathrm{HF}$ and loaded into the reactor.

The thickness and Ge content was determined by Rutherford backscattering on (100) substrates. For very thin layers on $\{111\},\{110\}$ or $\{311\}$ planes, the Ge concentration could not be measured. Therefore, the concentration values indicated during the paper are nominal values for growth on the (100) plane. The samples were characterized in addition by transmission electron microscopy (TEM) and photoluminescence spectroscopy (PL).

In order to achieve selective growth on patterned Si substrates the deposition on mask has to be suppressed. There are several mechanisms responsible for the selectivity of growth [15]: (i) etching by $\mathrm{HCL}$ by the reaction: $\mathrm{Si}+2 \mathrm{HCL} \rightleftharpoons \mathrm{SiCl}_{2}+\mathrm{H}_{2}$, (ii) reaction of the $\mathrm{SiO}_{2}$ mask with $\mathrm{Si}$ and $\mathrm{Ge}$ containing species forming volatile $\mathrm{SiO}$ and $\mathrm{GeO}$, respectively and (iii) adsorption of $\mathrm{H}_{2}$ on the $\mathrm{SiO}_{2}$ mask suppressing the nucleation of $\mathrm{Si}$ and Ge. If the mask is contaminated with carbon or metal residues the nucleation of $\mathrm{Si}$ and $\mathrm{Ge}$ on $\mathrm{SiO}_{2}$ is enhanced, which can lead to false interpretation of the selectivity [16].

The selective growth of $\mathrm{Si}$ and $\mathrm{SiGe}$ can be analysed using the supersaturation function [10]. It 
was concluded that selectivity in the $\mathrm{Si}-\mathrm{Ge}-\mathrm{Cl}-\mathrm{H}$ system is possible at all reasonable pressures ( 1 bar to $\left.10^{-3} \mathrm{mbar}\right)$ and at all adequate temperatures $\left(600-850^{\circ} \mathrm{C}\right)$ provided clean conditions [16] are available and the supersaturation is relatively low (for example: ratio of input partial pressure of $\mathrm{SiCl}_{2} \mathrm{H}_{2}$ to equilibrium partial pressure of $\mathrm{SiCl}_{2}$ below 1000 at $700^{\circ} \mathrm{C}$ ).

The growth rate and composition of $\mathrm{Si}_{1-x} \mathrm{Ge}_{x}$ generally depend on pad size [17]. When the growth is performed in the gas-phase transport regime the growth rate and composition are expected to depend on the filling factor, because the supersaturation is higher above the mask than above Si. The consequence are lateral concentration gradients of reactive species above the mask leading to a higher mass transport to the Si in the mask hole. Instead, when the growth is surface kinetic limited, for instance by reducing the total pressure, the growth proceeds at lower supersaturation and a more uniform growth is the result. Indeed, uniform growth (constant growth rate and composition) of $\mathrm{Si}_{1-x} \mathrm{Ge}_{x}$ was observed up to $\mathrm{x} \approx 0.3$ down to pad dimensions of $0.5 \mu \mathrm{m}$ by growing at 0.1 Torr and $700^{\circ} \mathrm{C}[10]$.

\section{RELAXATION OF $\mathrm{Si}_{1-x} \mathrm{Ge}_{x}$ IN SMALL PADS}

$\mathrm{Si}_{1-x} \mathrm{Ge}_{x}$ layers grown on $\mathrm{Si}$ substrates relax above a critical thickness. This thickness depends on the pad dimension and is shown in table 1 for large area, $100 \times 100 \mu \mathrm{m}^{2}$ and $10 \times 10 \mu \mathrm{m}^{2}$ square dots. One can see that for $\mathrm{x}=0.12$ the critical thickness for $10 \mu \mathrm{m}$ dots increases by more than 10 times, while for $x=0.20$ it is still five times larger than for large area samples. The reduction of misfit dislocation density by reducing the pad size can clearly be followed by photoluminescence spectroscopy [10].

The retardation of the onset of relaxation in small pads can not be explained by the elastic relaxation of the pads, at least for pads of the order of $100 \mu \mathrm{m}$ [12]. However, this phenomenon can be explained if kinetic barriers for nucleation of misfit dislocations are taken into account. Assuming that there are only few nucleation sites for misfit dislocations [18], but the self-multiplication and propagation processes are fast, then on large areas a dislocation nucleated at one of the few nucleation sites will propagate and multiplicate many times resulting in many dislocations. On small pads, however, either there are no nucleation sites at all, thus misfit dislocations can not be generated. Or, if a nucleation site is present, the generated misfit dislocation will propagate to the edge of the pad and will stop there, being unable to multiplicate significantly. Indeed, trying to count the dislocations in small pads, one is faced with the problem, that most of the pads are dislocation free, but there are some pads with misfit dislocations.

Table 1: Critical thickness in dependence on Ge content for large area, $100 \times 100 \mu \mathrm{m}^{2}$ pads and $10 \mathrm{x} 10 \mu \mathrm{m}^{2}$ pads grown at $700^{\circ} \mathrm{C}$;

\begin{tabular}{llll}
\hline $\mathrm{x}(\%)$ & $\begin{array}{c}\text { critical thickness/nm } \\
\text { for large area }\end{array}$ & $\begin{array}{c}\text { critical thickness/nm } \\
\text { for } 100 \times 100 \mu \mathrm{m}^{2}\end{array}$ & $\begin{array}{c}\text { critical thickness } / \mathrm{nm} \\
\text { for } 10 \times 10 \mu \mathrm{m}^{2}\end{array}$ \\
\hline 12 & 140 & $>600$ & $1200-200$ \\
\hline 16 & $<105$ & 220 & $>430$ \\
\hline 20 & $70-90$ & & 350 \\
\hline
\end{tabular}

\section{FACETS}

Under conditions leading to uniform and planar selective growth usually facets develop at the corner of the pads. The width of facets depends on the ratio of growth rate of the facet $R\{h k l\}$ and the 
growth rate in normal direction $R(100)$, while the development of a particular crystallographic plane depends on the alignment of the oxide side-wall along major crystal axes [11]. Under the conditions described in section 2 several planes occur [10].

(1) For sidewalls parallel to $\langle 110\rangle$ directions the $\{111\}$ and $\{311\}$ planes develop. Figure 1 a shows a $10 \mu \mathrm{m}$ wire of sample 880. The (100) quantum wells are planar and the (311) and (111) facets are clearly seen with the $\{111\}$ plane developing first, and from the beginning of the growth. At a later stage the $\{311\}$ planes develop.

(a)

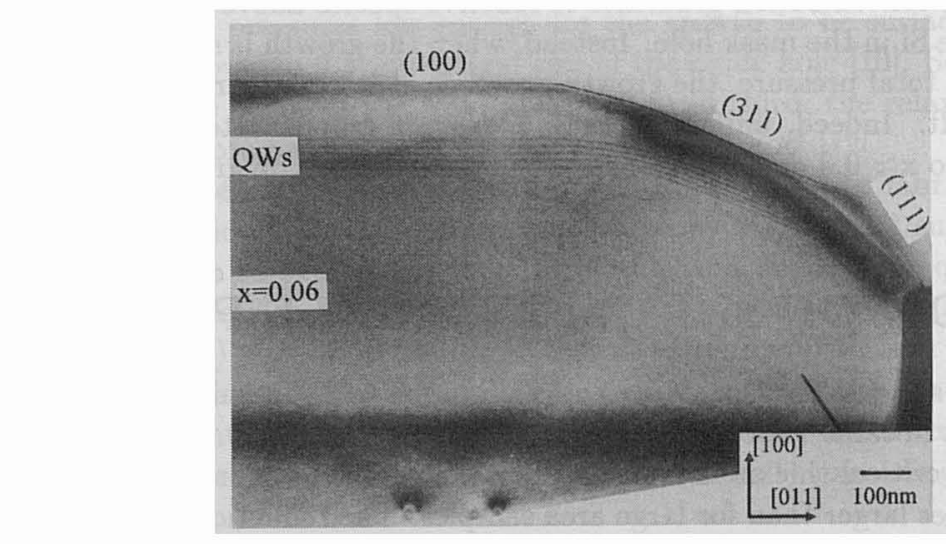

(b)

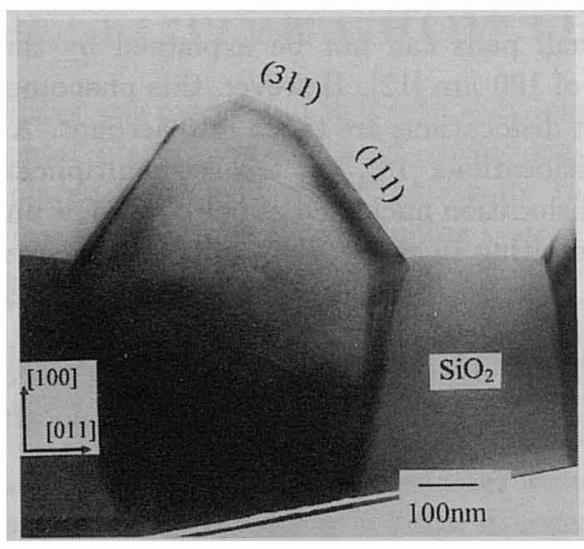

(c)

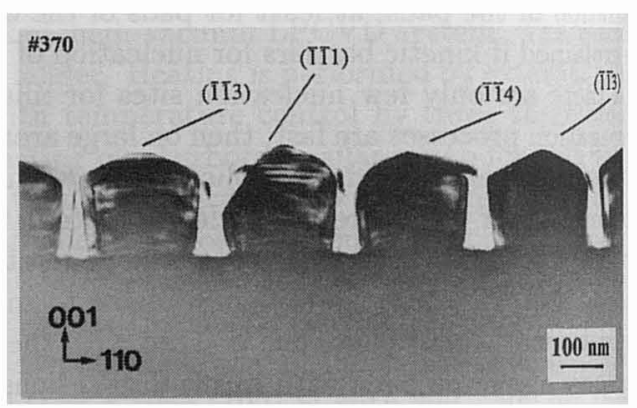

Figure 1: TEM cross sectional views of SiGe wires and dots with sidewalls parallel to $\langle 110\rangle$ : (a) $10 \mu \mathrm{m}$ wire consisting of a SiGe buffer $(\mathrm{x}=0.015), 200 \mathrm{~nm}$ thick, a second buffer $(\mathrm{x}=0.065), 670$ $\mathrm{nm}$ thick, five quantum well layers of $\mathrm{Si}_{0.70} \mathrm{Ge}_{0.30}, 1.7 \mathrm{~nm}$ thick separated by $15 \mathrm{~nm}$ SiGe $(\mathrm{x}=0.065)$ barriers, a SiGe cap $(x=0.065), 120 \mathrm{~nm}$ thick and $5 \mathrm{~nm} \mathrm{Si}$ on top (sample 880); (b) $0.4 \mu \mathrm{m}$ wire of sample 880 and (c) $0.18 \mu \mathrm{m}$ square dots (sample 370 ).

These planes were also reported for the Si/SiGe system by Aoyama et al. [19], however they observe the $\{111\}$ facet developing at a later stage. We think that these different observations are due to differences in the lateral oxide wall. When the oxide has no vertical wall the $\{311\}$ plane develops earlier.

The thickness of the structure in figure $1 \mathrm{a}$ in the planar (100) region of the $10 \mu \mathrm{m}$ wire is $890 \mathrm{~nm}$, the facet width is $800 \mathrm{~nm}$. This implies that $1 \mu \mathrm{m}$ structures and smaller should have no more planar (100) regions, i.e. only facets. Indeed, in figure $1 \mathrm{~b}$ the $0.4 \mu \mathrm{m}$ wire of sample 880 has a height of only $660 \mathrm{~nm}$ and no (100) plane. This result important for the interpretation of the PL spectra in 
section 5 .

In smaller oxide holes $(0.14-0.2 \mu \mathrm{m})$ additional planes such as $\{411\}$ and $\{433\}$ were observed (figure 1c). In contrast to larger pads such as $0.5 \mu \mathrm{m}$, where always the $\{111\}$ and $\{311\}$ facets are formed, in smaller holes either one or other facet develops. This phenomenon seems to be correlated to the growth in holes, which are much narrower than the surface diffusion length of the adsorbed species.
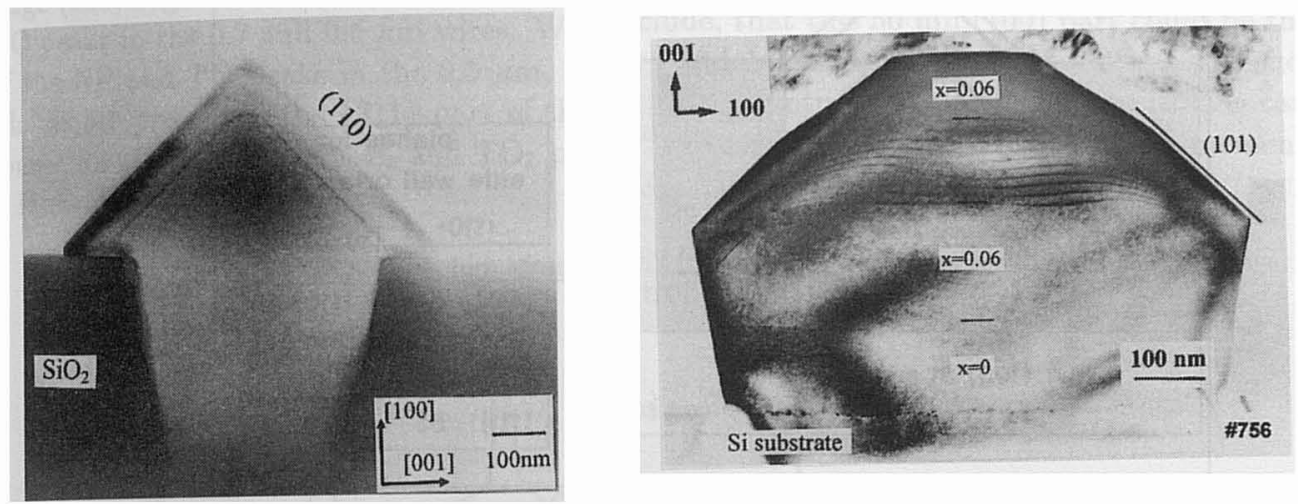

Figure 2: TEM cross sectional views of SiGe quantum well wires with sidewalls parallel to $\langle 100\rangle$. (a) $\mathrm{Si} / \mathrm{SiGe} / \mathrm{Si}$ wire $\left(0.4 \mu \mathrm{m}\right.$ width)) with a $1.5 \mathrm{~nm} \mathrm{Si}_{0.70} \mathrm{Ge}_{0.30}$ layer near the top of the structure (sample 558). (b) Wire with ten $\mathrm{QW}$ layers of $\mathrm{Si}_{0.70} \mathrm{Ge}_{0.30}, 2 \mathrm{~nm}$ thick separated by $15 \mathrm{~nm} \mathrm{SiGe}$ $(x=0.06)$ with a SiGe buffer $(x=0.06), 195 \mathrm{~nm}$ thick and a top SiGe layer (sample 756).

(2) For sidewalls parallel to $\langle 100\rangle$ directions the $\{110\}$ planes develop for Si and $\mathrm{SiGe}(\mathrm{x}=0.06$ and $\mathrm{x}=0.3$ ), both for free growth (overgrowth) and constrained growth (in the hole). In figure $2 \mathrm{a}$ there is an example of free growth revealing only the $\{110\}$ plane in a wire structure. The structure has a $1.5 \mathrm{~nm} \mathrm{Si}_{0.70} \mathrm{Ge}_{0.30}$ layer grown only on the facets. Figure $2 \mathrm{~b}$ shows an example for constrained growth and again the $\{110\}$ planes are seen. However, a second plane is seen, too, whose presence can not be understood so far.

Table 2: Growth rate on $\{110\},\{113\}$ and $\{111\}$ facets relative to (100) plane for different Ge contents; deposition temperature: $700^{\circ} \mathrm{C}$ and total pressure: 0.12 Torr.

\begin{tabular}{llll}
\hline $\mathrm{x}(\%)$ & $\mathrm{R}_{\{311\}} / \mathrm{R}_{\{100\}}$ & $\mathrm{R}_{\{110\}} / \mathrm{R}_{\{100\}}$ & $\mathrm{R}_{\{111\}} / \mathrm{R}_{\{100\}}$ \\
\hline 0 & & 0.5 & \\
\hline 0.06 & 0.63 & $0.33-0.41$ & 0.3 \\
\hline 0.30 & & $<0.26$ & \\
\hline
\end{tabular}

The results described above are summarized in figure 3 showing schematically a selectively grown multilayer wire on a (100) substrate. The assumption was made that the facets are generated from the beginning of the growth. The angle $\alpha_{h k l}$ is the angle between a $\{\mathrm{hkl}\}$ plane and the (100) plane. The experimentally determined growth rates of different facet planes are given in table 2 . Knowing the growth rate of a given $\{\mathrm{hkl}\}$ plane any structure can be drawn graphically if the angle $\alpha$ is known. This angle is given by 


$$
\tan \alpha=\frac{\sin \left(\alpha_{h k l}\right)}{\cos \left(\alpha_{h k l}\right)-r}
$$

where $\mathrm{r}=\frac{R_{h k s}}{R_{100}}$ is the growth rate ratio.

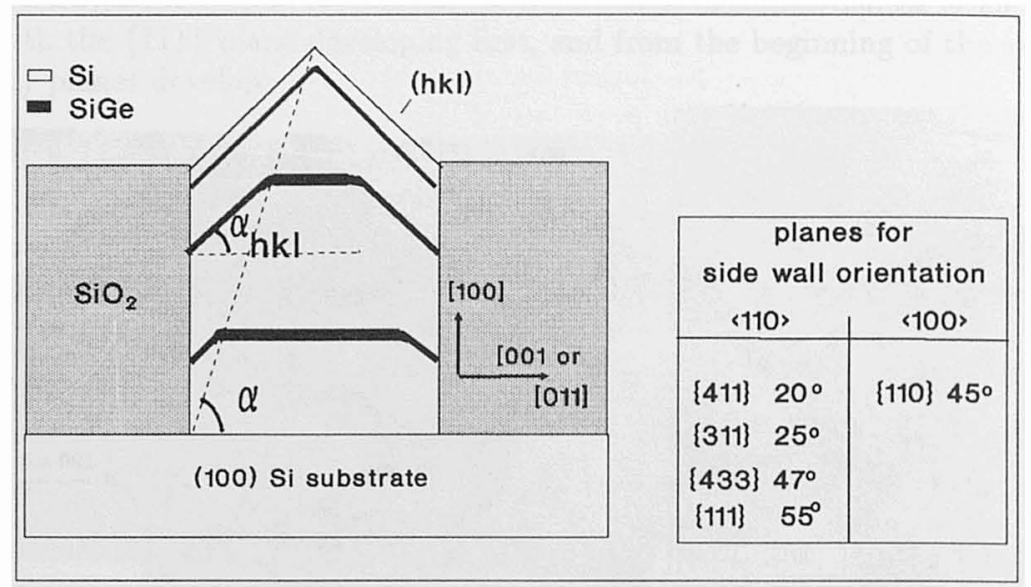

Figure 3: Schematic of a selectively grown wire with three SiGe layers grown between Si layers on a (100) substrate. The assumption was made that the faceting is not changed by the intermediate SiGe growth. The table shows the experimentally observed faceting planes for two different sidewall orientations; $\alpha_{h k l}$ is the angle between the crystallographic plane $\{h k l\}$ and the (100)plane

\section{PHOTOLUMINESCENCE OF SiGe QUATUM WELL WIRES}

Figure 4a displays PL spectra of six wire structures with sidewalls parallel to $\langle 110\rangle$ (sample 880, see also figure $1 \mathrm{a}$ and $\mathrm{b}$ ). The illuminated area with wires is $1 \mathrm{~mm}^{2}$ and contains approximately one thousand wires $1 \mathrm{~mm}$ long. For comparison the PL spectrum of an unpatterned area is also plotted. The PL spectra are dominated by the excitonic no-phonon (NP) peak and its transversal optical (TO) replica. All spectra have the same intensity scale. The buffer in the unpatterned sample is relaxed, as revealed by the misfit dislocation peaks $\mathrm{D} 1$ and $\mathrm{D} 2$, while the $3 \mu \mathrm{m}$ wires are almost strained as well as the smaller wire structures. The critical thickness for $\mathrm{x}=0.065$ is about $200 \mathrm{~nm}$ for large areas and by reducing the dot size below $10 \times 10 \mu \mathrm{m}^{2}$ it increases by more than 10 times (see section 3 ). In the case of wires some dislocations are present, because only one lateral dimension was reduced. This is seen in the PL spectra by a vanishingly small D2 peak. Therefore, one can consider the wires with dimensions $\leq 3 \mu \mathrm{m}$ as almost completely strained.

All wires have strong emission, even the $0.4 \mu \mathrm{m}$ ones. Several features can be evidenced. The 3 $\mu \mathrm{m}$ wires have in addition to the (100) quantum well peaks $\mathrm{NO}$ and $\mathrm{TO}$, two excitonic peaks labelled $\mathrm{NP}_{3}$ and $\mathrm{TO}_{3}$. The $\mathrm{NP}_{3}$ lies at $1102 \mathrm{meV}$ and corresponds very well with the strained excitonic gap of the buffer. The 0.5 and the $0.7 \mu \mathrm{m}$ wires have slightly blue shifted NP and TO peaks, while the $0.4 \mu \mathrm{m}$ wires have two new peaks, a no-phonon peak and a phonon-assisted one located $13 \mathrm{meV}$ at lower energy.

In order to understand these PL spectra one has to examine the TEM cross section of the $0.4 \mu \mathrm{m}$ wire shown in figure $4 \mathrm{~b}$. The height of the wire is only $660 \mathrm{~nm}$, as discussed in section 4 (see also 
figure $1 \mathrm{~b}$ ). The wire is shorter than in unpatterned regions because the facets from both sides made the junction. Therefore, the $0.4 \mu \mathrm{m}$ up to $1 \mu \mathrm{m}$ structures should have no (100) part any more. If no (100) portion of quantum well layers are left, the question arises where are the NP and TO peaks coming from. The TEM picture of figure $4 \mathrm{~b}$ shows, that in spite of the sharp $\{111\}$ and $\{311\}$ facets, the buried quantum well layers seem to be rounded, so that a (100) part could be present approximately $50 \mathrm{~nm}$ wide. In this region the quantum well layers seem to be thinner than in the large (100) region of the $10 \mu \mathrm{m}$ wire of figure 1a, which could explain the blue shift of the NP and TO peaks in the 0.7 and $0.5 \mu \mathrm{m}$ wires. We conclude, that this $50 \mathrm{~nm}(100)$ part could be the source of the NP and TO peaks in the $0.5 \mu \mathrm{m}, 0.7 \mu \mathrm{m}$ and $1 \mu$ wires. The TEM picture also shows that islands are present in the $\{311\}$ part of the multiple quantum well layers. These islands can be the source for the red shifted $\mathrm{NP}_{1}$ and $\mathrm{TO}_{1}$ peaks, because in the island region the confinement energy is lower.

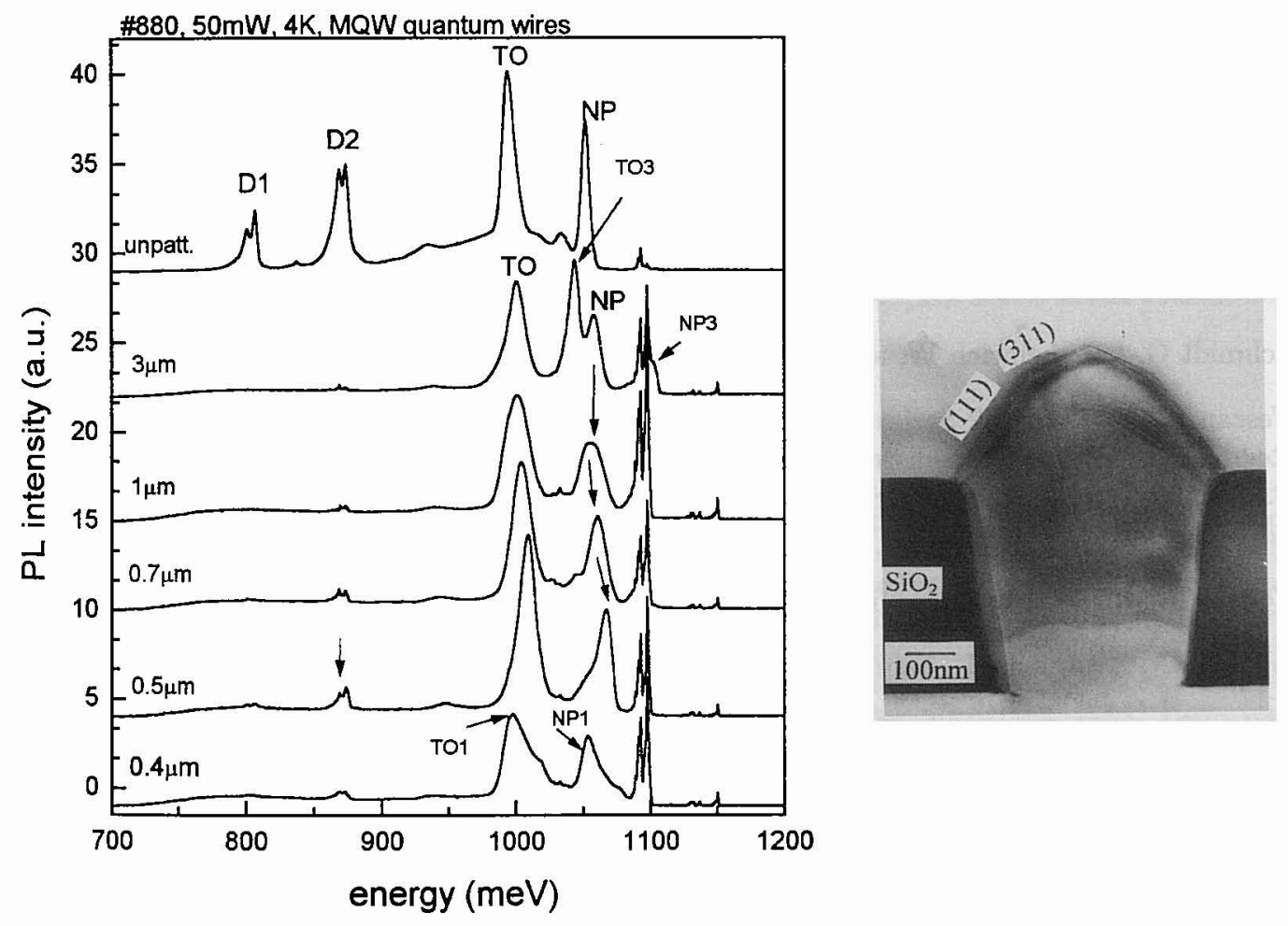

Figure 4: Wires oriented parallel to $\langle 110\rangle$ directions (sample 880); (a) Photoluminescence spectra and (b) TEM cross section of a $0.4 \mu \mathrm{m}$ wire

\section{CONCLUSIONS}

Selective epitaxy by LPCVD was applied to realize laterally confined strained multiple quantum well $\mathrm{SiGe}$ dots and wires in (100) plane. It was found that the extension of the (100) part of the structures depends on the sidewall orientation of the oxide holes. So far, $50 \mathrm{~nm}$ for $\langle 110\rangle$ sidewall orientation was achieved. However, in spite of sharp outer facets the inner (100) quantum well layers reveal a rounded form. Emission lines stronger than emission from the substrate were detected from quantum 
well layers on (100) plane, as well as from islands lying in $\{311\}$ planes.

Acknowledgements The authors are grateful to K. Schmidt for RBS measurements and K. Wambach for technical assistance.

\section{References}

[1] Weisbuch C. and Vinter B. Quantum semiconductor structures (Academic Press, Inc., Boston, 1991).

[2] Eaglesham D.J. and Cerullo M. Phys. Rev. Lett. 64 (1990) 1943-1946.

[3] Apetz R., Vescan L., Hartmann A., Dieker C. and Lüth H. Appl. Phys. Lett 66 (1995) 445-447.

[4] Usami N., Mine T., Fukatsu S. and Shiraki Y., Appl. Phys. Lett. 64 (1994) 539-541.

[5] Hartmann A., Vescan L., Dieker C. and Lüth H., J. Appl. Phys. (1995) in press.

[6] Tang Y. S., Wilkinson C.D.W., Smith D.W, Whall T.E. and Parker E.H. Jpn. J. Appl. Phys. 33 (1994) 2348-2352.

[7] Brunner P. Schlitenhelm J., Gondermann J., Spangenberg B., Hadam B., Köster T., Roskos H.G., Kurz H., Gossner H., Eisele I. and Abstreiter G. J. Cryst. Growth (1994) in press.

[8] Schmidt G, Langheinrich W. and Heime K. Solid State Electr. 37 (1994) 587-589.

[9] Vescan L., NATO Book Series "Low Dimensional Structures Prepared by Epitaxial Growth or Regrowth on Patterned Substrates" Ringberg Castle, Germany 20-24 February 1995, K.Eberl, P.M. Petroff and P. Demeester Eds. (Kluwer Acad. Publ., Dordrecht The Netherlands 1995) to be publ.

[10] Vescan L. Mat. Sci. and Eng. B28 (1994) 1-8.

[11] Ishitani, A, Kitajima, H., Tanno, K. and Tsuya, H. Microelectronic Engineering 4 (1986) 3-33.

[12] Stoica T. and Vescan L., J. Cryst. Growth 131 (1993) 32-40.

[13] Vescan L., Dieker C., Hartmann A. and A. van der Hart, Semic. Sci. and Techn. 9 (1994) 387-391.

[14] Tang H.P., Vescan L. and Lüth H., J. Cryst. Growth 116 (1992) 1-14.

[15] Goulding M.R., Mater. Sci. Eng. B17 (1993) 47-67.

[16] Sedgwick T.O., Agnello P.D., Berkenblit M. and Kuan T.S., J. Electrochem. Soc. 138 (1991) 3042-3047.

[17] Kamins T.I., Vook D.W., Yu P.K. and Turner J.E., Appl. Phys. Lett. 61 (1992) 669-671.

[18] Noble D.B., Hoyt J.L., King C.A. and Gibbons J.F., Appl. Phys. Lett. 56 (1990) 51-53.

[19] Aoyama, A., Ikarashi, T., Miyanaga, K. and Tatsumi, T. J. Cryst. Growth 136 (1994) 349-354. 